\title{
PRECONCEITO NIPO-BRASILEIRO COMO FATOR LIMITANTE NO APRENDIZADO
}

Vitória Miwa Minami Miyazaki

profvitoria3@gmail.com

\begin{abstract}
RESUMO
Com um mundo cheio de maldade, preconceito, violência, dificuldades sociais e familiares, tendo em vista essas diversas dificuldades colocando em ponto, o artigo tem como enfoque o preconceito nipo brasileiro como fator limitante no aprendizado, em vista de que temos várias diversidades culturais, encontrando, então, essa maldade no dia a dia. Além de encontrarmos preconceitos, temos uma questão da história por trás e como tudo começou, como as dificuldades durante a vinda dos primeiros imigrantes no Brasil no ano de 1908, no século XX. Mostrando como os japoneses tinham certas dificuldades financeiras, para voltar ao seu país natal e a questão de aprender uma língua nova. Com o período da Primeira e Segunda Guerra Mundial, isso se tornou mais complicado, onde os imigrantes que vieram estavam com intuito de poder vir assim que acabassem às duas guerras, porém nos dias 6 a 9 de agosto em 1945 o Japão foi bombardeado pelos Estados Unidos, onde tivemos cerca de 70 mil mortos.
\end{abstract}

Palavras-chave: Japão, Educação, História, Preconceito, Aprendizado. 


\section{INTRODUÇÃO}

Os descendentes do povo nipo-brasileiro, sofrem uma série de preconceitos antes da pandemia e com a pandemia. Não sabemos se isso é maldade ou algo ruim para os descendentes que vivem no Brasil, fazendo com que as suas diferenças culturais tenham uma relação no meio de dificuldades de forma clichê e preconceituosas.

As relações do preconceito sofreram devido às bombas de Hiroshima e Nagasaki, onde sofreu um desenvolvimento, onde o próprio país se tornou mais atacante na questão tecnológica, conhecidos por serem respeitados no mundo inteiro e além de encontrar formas de reinventar a forma de se viver. Os sentimentos da união do grupo, onde fortalece as brincadeiras sem graça, onde são conhecidos por "abre o olho, japonês!" ou "pastel de flango", mas um que os próprios estudantes sofrem de forma racial "nossa, o que você está fazendo num curso de humanas? Você não foi suficiente para passar em medicina ou engenharia?" Sabemos que não é nada fácil escutar frases desses estilos, inclusive até as crianças e jovens escutam essas frases, como "todo asiático é igual", ou "volta para o seu país", "mas você é japonês(a), coreano(a) ou chinês (a)? "Você deve ser boa em matemática!"

Mas com a pandemia essas frases aumentaram o nível que pessoas comentavam frases sobre o coronavírus, como: "vai embora para o seu país, você trouxe esse vírus ruim para o nosso país", com a pandemia essas citações aumentaram cada vez mais e não foi sobre no Brasil, outro país que sofreu com essa categoria de coisa, foi os Estados Unidos. Esse preconceito mesmo veio durante a imigração em meados do início do século XX no ano de 1908, esse preconceito iniciou a presença linguística dentro das colônias japonesas do passado, onde os imigrantes sofriam uma relação da sua própria classe social do brasileiro com o próprio estrangeiro, onde deveria ser valorizada à língua nacional (como o inglês e o próprio francês), mas na vinda ao Brasil os imigrantes não podiam em momento algum falar a língua materna, porque as próprias 
consequências seriam piores, pois alguns podiam ser sentenciado a morte ou ser presos por um tempo indeterminado.

Atualmente no século XXI, encontramos os estudantes de ensino médio nas redes públicas e privadas, escolhendo o caminho para o mercado de trabalho. Muitas vezes eles vão por escolha própria, ou, porque os pais querem que eles sigam a questão da geração familiar. Tivemos um estudo de encontrar uma forma que os próprios adolescentes com uma relação maior ao seu futuro da profissão como uma verdadeira conquista enriquecedora.

De acordo com Carvalho e Taveira (2009) realizaram uma pesquisa que investigou a percepção de professores, profissionais da área de orientação profissional, estudantes e de seus genitores a respeito da influência dos últimos no processo de escolha profissional dos filhos.

Tendo em vista um dos pontos do preconceito, podemos observar como o próprio interfere no aprendizado dos estudantes e durante a escolha profissional dos descendentes nipo-brasileiros. Olhando a partir das relações étnicas e culturais, o preconceito tem aumentado. No próprio Brasil essa questão do fluxo de imigrantes é em lugares diferentes, onde não conseguem mais ver sobre raça e que a cor ela fica em segundo lugar.

Os próprios descendentes sofrem e algumas pessoas observam que e os descendentes brancos ignoram os costumes, provocam a questão comportamental da cidade natal, devido ao novo vírus encontrado na China em dezembro de 2019, o mundo olhou no ocidental e envolvendo todos os asiáticos, ataques preconceituosos e cautelosos, onde escutavam comentários ofensivos, como: "Você não devia estar neste país, trouxe um vírus para o nosso mundo", ou até mesmo pessoas passavam perto de um asiático é passavam álcool e dizendo para ir embora. 
Durante as Olimpíadas de Tóquio ocorridas no Japão em Julho de 2021, tivemos uma forma de gesto pela representatividade e ação contra o racismo e preconceito durante a Cerimônia de Abertura das Olimpíadas, onde a tenista Naomi Osaka foi escolhida por acender a pira olímpica. A tenista nasceu no Japão, onde a mãe tem a nacionalidade japonesa e o seu pai é haitiano, mas com 3 anos a tenista migrou para os Estados Unidos com a família, mesmo sendo uma pessoa negra e por viver em outro país, a sua identidade acabou se tornando alvo de preconceito, nos dias de hoje se tornou principal pessoa da representatividade e das ações contra o preconceito nipo brasileiro e racismo. Em meados dos anos de 1924 a 1941 tivemos fases em que os próprios japoneses tiveram o grande auge de poder trabalhar em fazendas de cultivo de café, onde executavam diversos estados do Brasil, os imigrantes que vieram para o Brasil pensava em conseguir ter uma vida melhor no Brasil, mas, na verdade, foi o oposto, eles sofreram dificuldades durante os trabalhos, não podiam falar em japonês, tiveram que aprender o português para conseguir se comunicar e além de que a própria cultura não podia ser mostrada como vimos presentemente, caso tivesse as pessoas iam ser imediatamente pressas. O próprio Japão após a guerra se tornou um país independente com americanos vivendo um tempo no Japão, onde tiveram diversas ideias que estão prevalecendo atualmente, máquinas automáticas, facilitou o transporte, ou seja, os japoneses que quiserem voltar para o Japão poderia voltar com menos dias, sem ter uma viagem longa.

Um dos objetivos centrais do artigo, tem como enfoque a questão do aprendizado durante a escolha profissional, preconceito nos dias de hoje, cultura japonesa e o contexto histórico da Imigração Japonesa no século XX.

A forma da educação dos japoneses, coloca uma formação da educação, onde os próprios nipo-brasileiros, têm no Brasil, no começo do século XX (Dermartini 1995). Como comenta Miyao (1980, p. 91):

A revolução política e social iniciada na Era Meiji, em 1868, trouxe profunda transformação no regime da nação nipônica, dando prioridade à difusão da educação, difundindo-a de modo 
drástico, (...). Desde então o Japão emergiu de uma nação fechada, de 300 anos de isolacionismo, conseguindo rápida modernização com a introdução maciça da cultura ocidental. O japonês que viveu uma época assim peculiar sentia no seu âmago que a instrução era a coisa mais importante da vida, sobrepondo-se a qualquer outra opção. $\mathrm{O}$ imigrante japonês que começou a chegar ao Brasil em 1908 também foi criado nesse ambiente.

\section{METODOLOGIA}

Esta pesquisa foi elaborada pelo procedimento quantitativo, onde foi realizada uma pesquisa no Google Formulário, tendo 3 perguntas relacionadas a temática do artigo. As 3 perguntas feitas são:

- Geração (Issei: imigrantes japoneses; Nissei: filhos de japoneses; Sansei: netos de japoneses; Yonsei: bisnetos de japoneses; Nikkei: descendentes de japoneses nascidos fora do Japão);

- Se já foi alvo de preconceito;

- Preconceito pela escolha profissional escolhida para seguir;

- Preconceito com palavras maldosas na escola.

\section{RESULTADOS E DISCUSSÕES}

Diante as respostas das pessoas a primeira pergunta relacionada, foi voltada para geração onde pertencia, 106 pessoas colocaram serem Sansei; 30 delas são Yonsei; empate de 8 pessoas são Nikkeis e Nisseis e apenas 3 pessoas são Issei. Com o resultado obtidos na formação que na grande maioria das pessoas que responderam o formulário são Sansei, ou seja, os netos de pessoas vindas do Japão durante o período da Imigração, onde Japoneses estavam se mudando para o Brasil, com intuito de ter uma melhoria na vida, familiar e pessoal quanto financeira. 
Vendo grande parte que a maioria das pessoas descendentes de japoneses, são alvo de preconceito, ou seja, cerca por volta de $91,6 \%$ foram alvos de preconceito, sendo por meio verbal ou não verbal, essas dificuldades se tornam complicadas de ouvir nos dias de hoje é como se fosse ofender um negro e isso é considerado um ato de racismo. Em uma pesquisa realizada pela Revista VEJA publicada em 19 de agosto de 2020, comentam que se o Brasil é realmente considerado um país racista, e sim podemos afirmar que cerca de $61 \%$ as pessoas disseram que sim, o Brasil é considerado um país racista e $34,5 \%$ dizem que o Brasil não é racista.

Além dessa forte relação psicológica e social nos dias de hoje, estudantes de descendentes já sofreram ou sofrem preconceito pela escolha profissional que quer seguir, ou seja, muitos deles escolhem determinado curso, mas as pessoas do curso fazem comentários ofensivos, como, por exemplo: "Nossa, você não é boa em matemática? Por quê então você esta fazendo o curso de letras? Ou comentários ofensivos no aprendizado como: "Você deve ser bom em matemática.", palavras desse estilo e machucam, faz as pessoas se sentem menos desmotivadas, sentem ansiosas, começam sintomas com depressão ou até mesmo querer trocar de curso, cerca de $61,3 \%$ já sofreram isso e $38,7 \%$ relatam que nunca sofreram.

Além do cotidiano escolar temos o cotidiano fora da escola, onde pessoas comentam coisas que ninguém gostaria de ouvir, mas infelizmente, temos que ouvir e seguir em forte, essas palavras, são como, por exemplo: “Abre o olho japonês, pastel flango, todo asiático é igual, volte para o seu país, você é um monstro para o nosso país e entre outras palavras." Infelizmente não é somente aqui no Brasil que pessoas sofrem com essas situações, mas sim no mundo inteiro, cerca de 93,5\% já sofreram e ainda sofrem com palavras desse segmento e $6,5 \%$ relatam que não sofrem com isso.

\section{CONSIDERAÇÕES FINAIS}

No Japão as famílias encontram mais dificuldades de adaptação à cultura, além da jornada de trabalho excessiva e da não receptividade para com os estrangeiros. Tendo 
em vista esse cenário, tivemos a oportunidade de conhecer os documentos de auxílio criados pelo governo brasileiro e as alternativas que estão sendo desenvolvidas pelo governo japonês na esperança de sanar as dificuldades de professores e alunos no que diz respeito ao idioma, cultura e continuidade dos estudos. Identificamos também a realidade de alguns professores e apresentamos alternativas de educação para esse público. O objetivo deste artigo é compreender a história da imigração nipo-brasileira, apresentar as dificuldades enfrentadas por essa comunidade no que diz respeito à educação de seus filhos em contexto de dificuldades culturais e identitárias e conhecer as estratégias adotadas por ambos os governos, para proporcionarem melhores condições educacionais para essas crianças. Para alcançar tais objetivos, realizamos uma pesquisa qualitativa, analisando documentos governamentais e depoimentos de quatro pessoas para entender o problema e, assim, tentar diminuir os impactos negativos que afetam o processo educativo das crianças e jovens, apresentar propostas para que crianças descendentes tenham o apoio de profissionais capacitados. Nesse sentido, a pesquisa terá o apoio de pesquisa bibliográfica pertinente. Através dessa pesquisa, concluímos que a educação sempre foi um assunto importante para a comunidade nipo-brasileira e os familiares precisam estar envolvidos em todo o processo educacional do filho, priorizando a educação e tomando decisões que possibilitem um bom desempenho escolar dos filhos. Este estudo baseia-se em interesse pessoal sobre a questão, já que a autora, de ascendência japonesa, experienciou essa vivência.

Desejamos que esse artigo tenha contribuído com a sociedade acadêmica, dando continuidade aos estudos da comunidade nipo-brasileira, trazendo reflexões importantes sobre métodos de ensino para estrangeiros e que tenha proporcionado um direcionamento para as famílias de imigrantes relacionadas ao processo educacional dos filhos. Esperamos que, vivendo em um mundo cada dia mais globalizado, problemas relacionados à educação de estrangeiros deixem de existir. E que a educação no mundo caminhe para uma educação humana, formando sujeitos que reconheçam valores sociais e ambientais, respeitando a diversidade e a inclusão de todo indivíduo. 


\section{REFERÊNCIAS}

BRANDÃO, Carlos Rodrigues. O que é educação? 51ª ed. São Paulo: Brasiliense, 2009.

BRASIL: Ministério da Educação. Orientações gerais sobre o ensino para brasileiros no Japão. Brasília: MEC, 2018.

CALLIGARIS, Contardo. A adolescência. São Paulo: Publifolha, 2000.

CARVALHO, M. \& TAVEIRA, M. C. (2009). Influência de pais nas escolhas de carreira dos filhos: visão de diferentes atores. Revista Brasileira de Orientação Profissional, 10 (2), 33-41.

DEMARTINI, Zeila de B. F. Memórias de velhos mestres da cidade de São Paulo e seus arredores. Relatório de pesquisa. São Paulo: Ceru, 1988

DUCKITT, J. (1992) Psychology and prejudice - a historical analysis and integrative framework American Psychologist. 47. 1182-1193.

FREIRE, Paulo. Pedagogia da autonomia: saberes necessários à prática educativa. 40. ed. São Paulo: Paz e terra, 2009.

MAEYAMA, HIROSHI SAITO TAKASHI, Estudos brasileiros- Assimilação e Integração Japonesa no Brasil, ed. Vozes LTDA- Petrópolis, RJ, 1973, p. 129

Disponível em: http://www.imigrar.com,migração japonesa e o fenômeno dekassegui, acesso em: 16 de agosto de 2021

MIYAO, S. Posicionamento social da população de origem japonesa. In: SAITO (org.). A presença no Brasil São Paulo: T. A. Queiroz/ Eduardo 1980

MÜLlER, M. (1988). Orientação Vocacional: Contribuições clínicas e educacionais Porto Alegre: Artes Médicas.

NOGUEIRA, Maria Alice Nogueira. A escolha do estabelecimento de ensino pelas famílias: a ação discreta da riqueza cultural. Revista brasileira de educação. São Paulo, n.7, jan/fev/mar/abr, 1998. 
OHNO, Massao. Centenário da imigração japonesa no Brasil. São Paulo: Larousse do Brasil, 2008.

SOARES, D. H. P. A escolha profissional: do jovem ao adulto. São Paulo, Summus, 2002

SOUSA, A. O empresariado nipo-brasileiro no oeste paulista: de colono a industrial. 2010. 149 f. Dissertação (Mestrado em Geografia) - Programa de Pós-graduação em Geografia da FCT/UNESP - Universidade Estadual Paulista, Faculdade de Ciências e Tecnologia, Presidente Prudente, 2010.

SPARTA, M. BARDAGI, M. P., \& ANDRADE, A. M. J. (2005). Exploração vocacional e informação profissional percebida em estudantes carentes. Aletheia, $22,79-88$.

TERÊNCIO, M. G., \& SOARES, D. H. P. (2003). A internet como ferramenta para o desenvolvimento da identidade profissional. Psicologia em Estudo, 8(2), 139-145

UENO, LAURA SATOE. Migrantes em trânsito entre Brasil e Japão: uma intervenção psicossocial no retorno. 2008. Dissertação (Mestrado em Psicologia Social) -Instituto de Psicologia, University of São Paulo, São Paulo, 2008.

VIEIRA, FRANCISCA ISABEL SCHURIG, O japonês na frente de expansão paulista, ed. Universidade de São Paulo 1973, p. 155. 